\title{
A double-blind comparison of the effect of the antipsychotics haloperidol and olanzapine on sleep in mania
}

R.A. Moreno ${ }^{1}$, M.M. Hanna ${ }^{1,2}$,

S.M. Tavares ${ }^{2}$ and Y.P. Wang ${ }^{1,3}$
Correspondence

R.A. Moreno

Grupo de Estudos de Doenças Afetivas Instituto de Psiquiatria, HC, FMUSP

Rua Dr. Ovídio Pires de Campos, 785

05403-010 São Paulo, SP

Brasil

Fax: +55-11-3069-6648

E-mail: rmoreno@sti.com.br

Research supported by FAPESP (No. 99/07290-5).

Received June 7, 2006 Accepted December 13, 2006
${ }^{1}$ Departamento de Psiquiatria, Grupo de Estudos de Doenças Afetivas, ${ }^{2}$ Laboratório de Sono, Instituto de Psiquiatria, Hospital das Clínicas, Faculdade de Medicina, Universidade de São Paulo, São Paulo, SP, Brasil ${ }^{3}$ Departamento de Psiquiatria, Faculdade de Medicina, Universidade de Santo Amaro, São Paulo, SP, Brasil

\section{Abstract}

The effects of haloperidol and olanzapine on polysomnographic measures made in bipolar patients during manic episodes were compared. Twelve DSM-IV mania patients were randomly assigned to receive either haloperidol (mean \pm SD final dosage: $5.8 \pm 3.8 \mathrm{mg}$ ) or olanzapine (mean $\pm \mathrm{SD}$ final dosage: $13.6 \pm 6.9 \mathrm{mg}$ ) in a 6-week, double-blind, randomized, controlled clinical trial. One-night polysomnographic evaluation was performed before and after the haloperidol or olanzapine treatment. Psychopathology and illness severity were rated respectively with the Young Mania Rating Scale (YMRS) and the Clinical Global Impressions - Bipolar version (CGI-BP). There was a significant improvement in the YMRS and CGI-BP scores at the end of the study for both groups. Mixed ANOVA used to compare the polysomnographic measures of both drugs demonstrated significant improvement in sleep measures with olanzapine. In the olanzapine group, statistically significant time-drug interaction effects on sleep continuity measures were observed: sleep efficiency (mean \pm SEM pre-treatment value: $6.7 \pm 20.3 \%$; after-treatment: 85.7 $\pm 10.9 \%$ ), total wake time (pre-treatment: $140.0 \pm 92.5 \mathrm{~min}$; aftertreatment: $55.2 \pm 44.2 \mathrm{~min}$ ), and wake time after sleep onset (pretreatment: $109.7 \pm 70.8 \mathrm{~min}$; after-treatment: $32.2 \pm 20.7 \mathrm{~min}$ ). Conversely, improvement of polysomnographic measures was not observed for the haloperidol group $(\mathrm{P}>0.05)$. These results suggest that olanzapine is more effective than haloperidol in terms of sleeppromoting effects, although olanzapine is comparatively as effective as haloperidol in treating mania. Polysomnography records should provide useful information on how manic states can be affected by psychopharmacological agents.

\section{Introduction}

Sleep disturbances are prominent clinical features of manic states. Although some discrepant findings have been reported (1-3),
Key words

- Olanzapine

- Haloperidol

- Sleep

- Mania

- Bipolar disorder

- Polysomnographic

measurements 
shortened rapid eye movement (REM) latency, and increased REM density compared to their pre-morbid state (4-8) and compared to controls $(9,10)$.

Antipsychotic drugs have been prescribed for bipolar disorder patients for several decades as the treatment for psychotic symptoms or as an adjunctive therapy when other alternatives have failed, such as lithium and other mood-stabilizing drugs. However, the use of conventional antipsychotics in mood disorder patients is limited because of their side effects. Haloperidol is a well-known example of a high-potency dopamine $\mathrm{D}_{2}$ antagonist antipsychotic drug with florid extra-pyramidal side effects. Alternatively, some newer antipsychotics, e.g., olanzapine, risperidone, ziprasidone, quetiapine, and aripiprazole, have been tested to treat manic states $(11,12)$. The search for new drugs for the treatment of bipolar disorder has identified the novel atypical antipsychotic agent olanzapine, which has shown superior efficacy when compared with placebo in clinical trials (13) and seems to be as effective as lithium in treating acute mania (14). There is also some evidence that olanzapine is effective in some bipolar patients who are refractory to other conventional treatments (15). The favorable tolerability profile of olanzapine might be due to its affinity at dopaminergic $\mathrm{D}_{1}-\mathrm{D}_{4}$, serotonergic $\left(5-\mathrm{HT}_{2,3,6}\right)$, muscarinic (subtypes 1-5), adrenergic ( $\alpha-1)$, and histaminergic $\left(\mathrm{H}_{1}\right)$ binding sites (11). The main PSG finding for olanzapine tested on healthy subjects is an increase of slow-wave sleep (16-18).

The lack of studies evaluating the effects of antipsychotics on the sleep of manic patients represents a major gap in the literature. A number of investigators have argued that the degree of sleep disturbance relates to the duration of manic episodes, and therefore treating sleep disturbances may be useful for acutely manic patients by reducing the time needed for recovery (19-21). The aim of the present study was to compare the effects of haloperidol and olanzapine on the PSG profile of bipolar manic patients.

\section{Subjects and Methods}

\section{Subjects}

The subjects included in the study met the DSM-IV's (22) criteria for bipolar disorder, acute manic phase, with or without psychotic characteristics. All patients were interviewed by trained psychiatrists using the Structured Clinical Interview for DSMIV Axis I Disorders - Patient Edition, version 2.0 (SCID-I/P) (23). Patients were accepted into the study if they had not switched from a depression phase to mania, or from a mania phase to depression, within 1 month before or after the PSG procedure. Baseline psychopathology, as rated by the Young Mania Rating Scale (YMRS) (24), had to score higher than 20 on the occasion of both visits 1 and 2 for the patient to remain in the study.

Originally, 19 eligible patients were recruited from the Mood Disorder outpatient unit of the Institute of Psychiatry (Grupo de Estudos de Doenças Afetivas) to participate in the study. All recruited patients were hospitalized during the study. Seven patients were subsequently excluded from the trial due to the following reasons: 1 patient refused to be enrolled, 3 patients withdrew consent, and 3 patients received non-allowed medication. The final sample of 12 bipolar patients comprised 9 females and 3 males, with a mean age of 38.8 years (range: 22 to 62 years). Socio-demographic information, previous episode, and past mood illness history are shown in Table 1.

Ideally, the patients should have been medication-free for at least 2 weeks before the trial. Only 4 patients ( 1 in the haloperidol group and 3 in the olanzapine group) were not taking the medication when fulfilling the inclusion criteria. For 8 medicated patients (5 were on antipsychotics, 2 were on a com- 
bination of antipsychotics and lithium, and 1 was on antidepressants), a washout period of at least 4 days was utilized prior to the trial. The rationale for the short washout period was based on the practical difficulties of managing severely disturbed patients in the hospital setting. None of our study patients was on depot long-acting antipsychotics before starting the recording. The only psychotropic drug allowed for both groups was zolpidem, $10 \mathrm{mg} /$ day, but not on the night of recording. To ensure patients were substancefree, all underwent urinalysis drug screening before the PSG study. Urinalysis was carried out to detect the possible use of phencyclidine, benzodiazepines, amphetamines, barbiturates, cannabis, cocaine, methadone, and opiates. Patients who presented a serious general medical condition or neurological disease were excluded. Clinical evidence of primary sleep disorder or a previous history of drug or alcohol abuse were also criteria for excluding patients.

The study was approved by the School of Medicine of the University of São Paulo Ethics Committee and was conducted in accordance with the Helsinki Declaration of 1975. Written informed consent was obtained from participants, or the person legally responsible for them, before the study.

\section{Study design}

Patients were randomly and consecutively assigned to treatment with either olanzapine, $15 \mathrm{mg} /$ day (7 subjects: 3 males, 4 females; mean age: 38.6 years, range: $22-62$ ), or haloperidol, $10 \mathrm{mg} /$ day (5 subjects, all females; mean age: 39.2 years, range: $23-49$ ) in a double-blind design. The duration of treatment ranged from 31 to 51 days (mean $\pm \mathrm{SD}$, $43.7 \pm 4.9$ days, or approximately 6 weeks). The olanzapine group $(42.3 \pm 5.5$ days $)$ did not differ significantly $(\mathrm{P}>0.05)$ from the haloperidol group (45.6 \pm 3.8 days) in terms of treatment days. Both drugs could be flexibly adjusted within the therapeutic range as clinically warranted (olanzapine, $5-20 \mathrm{mg}$ / day; haloperidol, 3-15 mg/day). Furthermore, the two drugs to be compared had the same appearance and were packaged identically, and matched in order to satisfy the requirements of a double-blind study. Patients performed the PSG sleep study immediately before (pre-treatment or time zero) and again 6 weeks after (post-treatment or time one) olanzapine or haloperidol treatment. Most of the patients performed the second PSG recording on or about the 42nd day. Two patients performed the second PSG test before the 42nd day according to the criteria of

$\begin{aligned} & \text { Table 1. Demographic variables of maniac patients and previous illness of the haloperidol and olanzapine } \\
& \text { groups at baseline. }\end{aligned}$
\begin{tabular}{lcc}
\hline Parameter & $\begin{array}{c}\text { Haloperidol group } \\
(\mathrm{N}=5)\end{array}$ & $\begin{array}{c}\text { Olanzapine group } \\
(\mathrm{N}=7)\end{array}$ \\
\hline Age (mean \pm SD in years) & $39.2 \pm 11.2$ & $38.6 \pm 14.2$ \\
Female/Male & $5 / 0$ & $4 / 3$ \\
Mean number of previous manic episodes & $7.6(0-19)$ & $4.4(0-12)^{*}$ \\
Mean number of manic episodes in the last year & $0.2(0-1)$ & $0.5(0-1)$ \\
Mean age (in years) at onset of manic symptoms & $31.0(23-49)$ & $29.9(18-50)$ \\
Mean number of previous depressive episodes & $4.2(0-20)$ & $6.3(0-14)$ \\
Mean number of depressive episodes in the last year & $0.2(0-1)$ & $1.1(0-4)^{*}$ \\
Mean age (in years) at onset of depressive symptoms & $35.0(26-47)$ & $36.0(20-45)$ \\
Mean number of previous admissions & $2.3(0-8)$ & $2.9(0-11)$ \\
Psychotic features during mood episodes & $5(100.0 \%)$ & $5(71.4 \%)^{*}$
\end{tabular}

Data are reported as mean number or age of patients with range in parentheses or as indicated in table. ${ }^{*} \mathrm{P}<0.05$ compared to the haloperidol group (ANOVA). 
lowering either Clinical Global Impression Bipolar version (CGI-BP) or YMRS scores.

\section{Polysomnographic procedures}

PSG recording was performed with a 21channel polygraph (Nihon-Kohden, neurofax, EEG 4400 series, Washington, DC, USA) within a sleep laboratory. Full-montage clinical PSG parameters were used, including electroencephalogram (C3/A2; C4/ $\mathrm{A} 1$; sensitivity, $70 \mu \mathrm{V} / \mathrm{cm}$; high-pass filter, $0.5 \mathrm{~Hz}$; low-pass filter, $70 \mathrm{~Hz}$ ), electrooculogram (sensitivity, $70 \mu \mathrm{V} / \mathrm{cm}$; high-pass filter, $0.5 \mathrm{~Hz}$; low-pass filter, $70 \mathrm{~Hz}$ ), submental electromyogram (sensitivity, $2 \mu \mathrm{V} /$ $\mathrm{cm}$; low-pass filter, $5 \mathrm{~Hz}$; high-pass filter, 70 $\mathrm{Hz}$ ), electromyogram of the anterior tibialis muscle to assess periodic leg movements (sensitivity, $10 \mu \mathrm{V} / \mathrm{cm}$; high-pass filter, 5 $\mathrm{Hz}$; low-pass filter, $70 \mathrm{~Hz}$ ), and respiratory monitoring and electrocardiogram, as recommended by Rechtschaffen and Kale's standardized guidelines (25). Paper speed was $10 \mathrm{~mm} / \mathrm{s}$. The first sleep recording time started at 10 to $12 \mathrm{pm}$ except for 1 patient whose first sleep recording time began at 1:37 am, and the second sleep recording time started at 10 to $12 \mathrm{pm}$ for all patients except 3 (0:24 to 1:00 am). We performed all-night PSG evaluation for one night during the patient's usual sleeping time before admission to the study and about 42 days after treatment. On sleep-study days, patients were not allowed to take daytime naps.

\section{Measurements and sleep polysomnographic variables}

Baseline psychopathology and clinical severity were rated by the YMRS and the CGI-BP, respectively. Both scales were rated weekly from baseline until the end of the trial. The following scales were used to rate the intensity of side effects: Abnormal Involuntary Movement Scale (AIMS), Barnes Akathisia Rating Scale (BARS), and UKU
Side Effect Rating Scale. The PSG measurements of sleep parameters for pre- and posttreatment records are detailed below.

The YMRS comprises 11 questions on heightened mood, manic behavior and cognition rated with a Likert severity scale ranging from 0 to 4 (14). The YMRS is the most widely used rating scale for manic patients, with evidence of well-established reliability and validity.

The CGI-BP for the severity of illness is a modified version of the original Clinical Global Impression for rating the severity of manic and depressive episodes and the degree of change (26). The score ranges from 0 to 7 on the Likert scale. The revised scale provides a focused set of instructions to facilitate interrater reliability.

Sleep parameters were scored visually by one of the authors (SMT) according to Rechtschaffen and Kale's criteria (25). The rater was blind to the medication status and psychiatric condition of the patient. The following 3 groups of sleep outcome were measured as continuous variables:

Sleep continuity indexes. These indexes include total recording time, total sleep time, sleep efficiency (total recording period in relation to total sleep time), sleep latency (time from the beginning of the recording period to the onset of stage 2 sleep for at least 10 uninterrupted min), slow wave sleep (SWS) latency (the time between sleep onset and the first SWS period), total wake time (intermittent wakefulness that is bound by sleep), wake after sleep onset, and number of awakenings. All intervals were measured in minutes.

Sleep architecture indexes. These indexes correspond to percent time spent asleep in different stages of sleep. The time of each stage is reported in minutes, percentage of sleep period time, and their distribution by fractions of night. Non-REM sleep was defined as the sum of stages 1,2,3, and 4 of sleep, taken as a percentage of sleep period time. In contrast, SWS or delta sleep was 
defined as the sum of stages 3 and 4 of sleep, taken as a percentage of sleep period time.

REM sleep indexes. These indexes include REM latency (the time between sleep onset and the first REM period, minus any wakefulness occurring during the interval), total REM time, total REM activity (sum of visually scored eye movement density from each 60-s REM epoch, on a 0 to 8 Likert scale), and total REM density (rate of REM activity divided by REM time).

\section{Statistical analysis}

Sociodemographic and PSG variables are reported as means, standard deviation (SD) or range. Fisher's exact test was used to compute binary outcome. For continuous outcome, the Student $t$-test and analysis of variance (ANOVA) were chosen to identify between-group differences and associations. All tests were two-tailed, with the level of significance set at 0.05 .

To further explore the differential effect of medication on sleep measures, the mixed between-within subject ANOVA design was chosen to select those PSG variables (dependent or criterion variables) which presented a time-drug interaction effect, time effect and drug effect for the type of treatment drug (haloperidol or olanzapine) and the time frame of trial (before and after intervention). These two latter variables are considered to be independent or predictor variables. Mixed ANOVA is an extension of the repeated measure design, and allows simultaneous comparison of the betweengroup design (olanzapine or haloperidol), and within-group or repeated measure design (pre-intervention and after intervention). The $F$ statistic was used to calculate the ratio of variance due to the effects to the variance due to error. Its level of significance was set at $\alpha=0.05$. For the variables selected by ANOVA the post hoc paired-sample $t$-test was used to compare the mean score for each group on two different occasions (before and after intervention), separately for the olanzapine and haloperidol group. All statistical analyses were performed using the SPSS package (Chicago, IL, USA).

\section{Results}

The mean final dosage for the haloperidol group was (mean $\pm \mathrm{SD}$ ) $5.8 \pm 3.8 \mathrm{mg}$ (range 3-10 mg) or $290 \mathrm{mg}$ chlorpromazine equivalent, and the mean dosage for the olanzapine group was $13.6 \pm 6.9 \mathrm{mg}$ (range $5-20 \mathrm{mg}$ ) or $272 \mathrm{mg}$ chlorpromazine equivalent. There was no statistically significant difference between the final dosage of two types of antipsychotics (Student $t$-test $=1.52$; $P>0.05)$. At the end of the trial, the two groups did not differ significantly concerning the overall side effects as measured by AIMS, BARS and UKU. The study sample was severely ill, as demonstrated by the high YMRS and CGI-BP scores at baseline. Additionally, pre-treatment YMRS and CGIBP scores were similar $(\mathrm{P}>0.05)$ for both groups (Table 2). After treatment with haloperidol, the study group showed a significant $(\mathrm{P}=0.003)$ decrease in YMRS and CGI-BP scores. The group treated with olanzapine also showed a significant $(\mathrm{P}<$ 0.05 ) decrease from the beginning to the end of the experiment in both YMRS total scores and CGI-BP scores. However, the differences between drugs were not statistically significant $(\mathrm{P}>0.05)$. Thus, the two drugs were similar in efficacy in reducing total

Table 2. Comparison of Young Mania Rating Scale (YMRS) and Clinical Global Impression - Bipolar version (CGI-BP) scores for the haloperidol ( $\mathrm{N}=5)$ and olanzapine $(\mathrm{N}=7)$ groups before and after treatment.

\begin{tabular}{lcclcc}
\hline \multirow{2}{*}{ Scale } & \multicolumn{2}{c}{ Haloperidol group } & & \multicolumn{2}{c}{ Olanzapine group } \\
\cline { 2 - 3 } \cline { 5 - 6 } & Before treatment & After treatment & & Before treatment & After treatment \\
\hline YMRS & $30.6 \pm 8.6$ & $4.8 \pm 10.7^{*}$ & & $30.6 \pm 5.0$ & $10.4 \pm 13.8^{*}$ \\
CGI-BP & $13.0 \pm 2.0$ & $4.6 \pm 3.6^{*}$ & & $11.3 \pm 1.8$ & $6.4 \pm 3.0^{*}$ \\
\hline
\end{tabular}

Data are reported as mean \pm SD.

${ }^{*} \mathrm{P}<0.05$ compared to pre-treatment (Student $t$-test). 
YMRS and CGI scores for manic patients.

To determine whether the changed score of a particular variable was followed by an increase/decrease in manic episodes, each PSG variable (difference between pre- and post-treatment values) was tested for association with YMRS and CGI variations. There was no significant correlation between PSG variables and clinical rating scales (data not shown). The baseline PSG measures for the presence of psychotic features was similar $(\mathrm{P}>0.05)$ for psychotic manic patients and for those without psychotic symptoms.

Table 3 presents the mean \pm SD values of PSG variables for both groups. At baseline, the olanzapine group showed significantly greater total wake time $(\mathrm{P}<0.05)$ and time awake after sleep onset $(\mathrm{P}<0.05)$ compared to the haloperidol group. Additionally, the olanzapine group presented significantly less efficient sleep $(\mathrm{P}<0.05)$. The remaining PSG variables were largely similar between the two treatment groups. It should be pointed out that there was no correlation between the starting time of first and second sleep recordings and REM sleep latency.

Moreover, mixed ANOVA statistics were used to compute the following effects: effect of time-drug interaction, time effect and drug effect for both groups. Three sleep continuity variables emerged as significant $(\mathrm{P}=$ 0.02 ) for time-drug interaction effect: total wake time, wake time after sleep onset, and sleep efficiency. A time effect for both groups could be observed for total REM activity ( $\mathrm{P}$ $=0.04)$ and SWS distribution by fraction of

Table 3. Time-drug interaction effect, main effect of time and drug on polysomnographic measures for the haloperidol $(\mathrm{N}=5)$ and olanzapine $(\mathrm{N}=$ 7) groups, unmedicated and 6 weeks after medication.

\begin{tabular}{|c|c|c|c|c|c|c|c|}
\hline \multirow[t]{2}{*}{ Measure } & \multicolumn{2}{|c|}{ Haloperidol } & \multicolumn{2}{|c|}{ Olanzapine } & \multicolumn{3}{|c|}{ ANOVA (P value)* } \\
\hline & Unmedicated & Medicated & Unmedicated & Medicated & Time-drug & Time & Drug \\
\hline \multicolumn{8}{|l|}{ Sleep continuity variables } \\
\hline Total sleep time (min) & $356.1 \pm 85.2$ & $343.8 \pm 136.0$ & $280.0 \pm 91.5$ & $325.2 \pm 54.3$ & NS & NS & NS \\
\hline Number of awakenings (>30") & $14.4 \pm 6.2$ & $31.4 \pm 24.3$ & $21.3 \pm 11.1$ & $20.0 \pm 6.5$ & NS & NS & NS \\
\hline Total wake time (min) & $32.5 \pm 25.2$ & $94.0 \pm 104.3$ & $142.0 \pm 92.5$ & $55.2 \pm 44.2$ & 0.02 & NS & NS \\
\hline Time awake after sleep onset (min) & $39.1 \pm 25.8$ & $75.1 \pm 79.3$ & $109.7 \pm 70.8$ & $32.2 \pm 20.7$ & 0.02 & NS & NS \\
\hline Sleep efficiency $(\%)$ & $89.8 \pm 7.6$ & $76.8 \pm 27.9$ & $66.7 \pm 20.3$ & $85.7 \pm 10.9$ & 0.02 & NS & NS \\
\hline Sleep latency (min) & $11.6 \pm 19.9$ & $32.3 \pm 31.7$ & $62.9 \pm 102.9$ & $15.5 \pm 15.3$ & NS & NS & NS \\
\hline SWS latency (min) & $40.5 \pm 35.9$ & $76.7 \pm 115.0$ & $25.5 \pm 25.3$ & $19.8 \pm 11.7$ & NS & NS & NS \\
\hline \multicolumn{8}{|l|}{ Sleep architecture } \\
\hline Stage 1 (\% SPT) & $6.2 \pm 8.6$ & $5.7 \pm 6.6$ & $4.4 \pm 5.8$ & $4.5 \pm 2.9$ & NS & NS & NS \\
\hline Stage 2 (\% SPT) & $59.3 \pm 16.3$ & $43.9 \pm 18.8$ & $43.4 \pm 14.8$ & $39.8 \pm 10.3$ & NS & NS & NS \\
\hline Stage 3 (\% SPT) & $3.3 \pm 2.4$ & $2.0 \pm 2.1$ & $3.4 \pm 3.1$ & $4.9 \pm 4.0$ & NS & NS & NS \\
\hline Stage 4 (\% SPT) & $5.2 \pm 5.5$ & $11.4 \pm 12.7$ & $12.3 \pm 11.8$ & $18.5 \pm 16.7$ & NS & NS & NS \\
\hline SWS (\% SPT) & $8.5 \pm 6.0$ & $13.4 \pm 14.7$ & $15.7 \pm 12.8$ & $23.4 \pm 17.4$ & NS & NS & NS \\
\hline Stage REM (min) & $73.8 \pm 24.6$ & $70.9 \pm 43.4$ & $61.6 \pm 38.0$ & $81.6 \pm 28.2$ & NS & NS & NS \\
\hline Stage REM (\% SPT) & $20.0 \pm 5.7$ & $16.9 \pm 10.3$ & $16.3 \pm 8.6$ & $22.5 \pm 6.2$ & NS & NS & NS \\
\hline 1st night fraction SWS distribution & $23.3 \pm 30.7$ & $31.7 \pm 30.9$ & $29.2 \pm 35.5$ & $57.8 \pm 30.2$ & NS & 0.01 & NS \\
\hline 2nd night fraction SWS distribution & $9.8 \pm 10.6$ & $21.5 \pm 25.7$ & $15.2 \pm 12.7$ & $29.2 \pm 31.2$ & NS & NS & NS \\
\hline 3rd night fraction SWS distribution & $3.0 \pm 6.8$ & $4.3 \pm 5.7$ & $3.9 \pm 9.6$ & $11.2 \pm 11.8$ & NS & NS & NS \\
\hline \multicolumn{8}{|l|}{ REM measures } \\
\hline REM latency (min) & $84.4 \pm 86.0$ & $55.6 \pm 29.4$ & $33.6 \pm 35.7$ & $79.7 \pm 43.9$ & NS & NS & NS \\
\hline Total REM activity & $39.1 \pm 23.7$ & $66.7 \pm 36.0$ & $56.0 \pm 28.1$ & $96.0 \pm 63.4$ & NS & 0.04 & NS \\
\hline Total REM density & $0.6 \pm 0.2$ & $0.8 \pm 0.4$ & $0.8 \pm 0.2$ & $1.3 \pm 0.7$ & NS & NS & NS \\
\hline
\end{tabular}

Data are reported as mean \pm SD. SWS = slow wave sleep; \% SPT = percentage of sleep period time; REM = rapid eye movement.

${ }^{*}$ Effect of time-drug interaction, main effects of time and drug, respectively, for $F$ statistics. ANOVA was used to compare olanzapine and haloperidol. NS = non-significant. 
night during the first third of the night $(\mathrm{P}=$ 0.01). No significant drug effect was observed for any PSG measure.

A graphic representation of significant PSG measures is found in Figure 1. Post hoc pairedsample $t$-tests performed separately for each treatment group showed a difference between treatment groups. The olanzapine group significantly changed from baseline regarding total wake time $(t=-3.16 ; 95 \% \mathrm{CI}=-154.1$, -19.6; $\mathrm{P}=0.020)$, wake time after sleep onset $(t=-3.05 ; 95 \% \mathrm{CI}=-78.8,-201.6 ; \mathrm{P}=0.023)$, and sleep efficiency $(t=3.11 ; 95 \% \mathrm{CI}=4.0$, 33.9; $\mathrm{P}=0.021)$. The effect size of the variations detected was large: eta-squared was 0.62 , 0.61 , and 0.62 for total wake time, wake time after sleep onset and sleep efficiency, respectively. For the haloperidol group, a time-drug interaction effect could not be demonstrated $(\mathrm{P}>0.05)$.

\section{Discussion}

The present randomized double-blind study is the first longitudinal investigation of the effects of conventional and atypical antipsychotic treatment on night sleep in mania. The major findings suggested that although the efficacy of olanzapine appears to be comparable to that of haloperidol for the treatment of acute mania, olanzapine seems to be more effective than haloperidol in improving the continuity measures of the sleep pattern in manic patients.

Olanzapine was as effective as haloperidol in the treatment of manic states, as demonstrated by the decrease in total YMRS score and in severity ratings of mania on the CGI-BP. Although a slight difference concerning previous illness history, in terms of number of episodes, was identified between the two groups, the psychopathology and severity of both groups at baseline were mostly similar. The inclusion criterion we adopted was the presence of at least one manic episode during the past year. At baseline, however, the haloperidol group did have better sleep efficiency, longer total sleep time, lower total wake time, and time awake after sleep onset, than the olanzapine group at baseline. Nevertheless, none of the pre- or post-treatment clinical variables showed a significant correlation with the various sleep variables examined $(21,27)$. These baseline differences should be kept in mind when interpreting the PSG data.

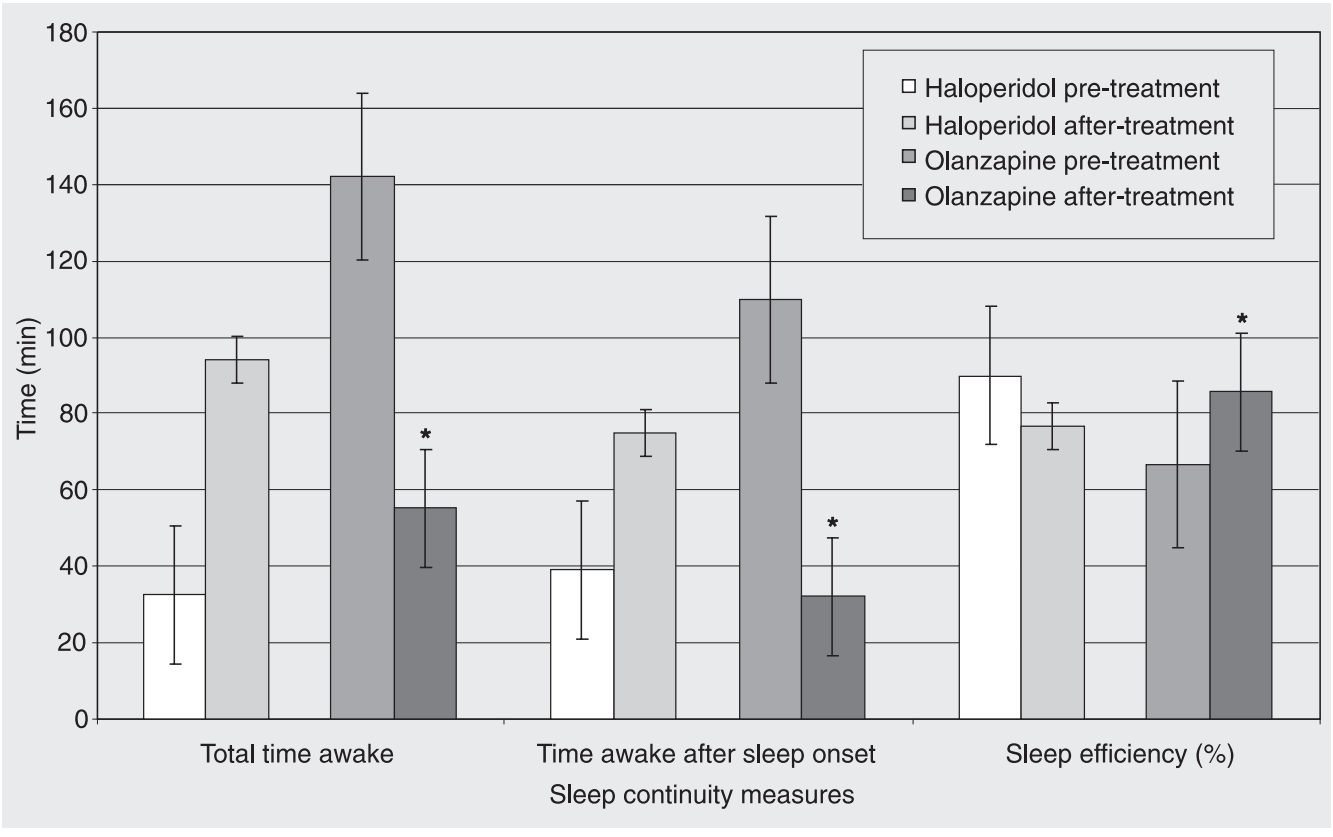

Figure 1. Comparison of polysomnographic measures with time-drug interaction effects after application of the mixed ANOVA model to the haloperidol $(\mathrm{N}=5)$ and olanzapine $(\mathrm{N}=$ 7) groups. ${ }^{*} P<0.05$ compared to the pre-treatment period (post hoc paired-sample $t$-test). 
The results of the present study suggest that atypical and conventional antipsychotic drugs appear to differ in their effects on some PSG measures in mania. Overall sleep improvement was due to increased sleep continuity parameters, sleep stages 2 and 4, REM sleep, and first fraction of night SWS.

Poor sleep continuity is a nonspecific feature and may occur in several psychiatric disorders, such as depression, generalized anxiety disorders, and obsessive-compulsive disorder (3). In the present study, a significant improvement in sleep continuity measures was observed only for the olanzapine group of manic patients. The validity and consistency of this finding were documented by the evidence of the interaction effect of olanzapine on sleep continuity indexes, with a significant difference between pre- and post-treatment values for these measures, along with a large effect size. A trend of interaction in terms of number of awakenings was also observed. Similarly, previous studies (16-18) also reported this sleep-promoting benefit for olanzapine in healthy volunteers. Sleep continuity and sleep architecture indexes were not significantly changed after haloperidol administration.

The time-drug interaction effect for the atypical antipsychotic group on sleep continuity indexes indicated that the sleep-promoting effect of olanzapine (type of treatment drug) did indeed depend on the effect of time of trial (before or after intervention). A possible explanation for this may be the effects of many receptors mediated by antipsychotic agents, a combination of them, or via blockade of histamine- $\mathrm{H}_{1}$ receptors (28) or $5-\mathrm{HT}_{2 \mathrm{~A} / 2 \mathrm{C}}$ (29). Alternatively, the result may reflect the slight baseline difference between the treatment groups in sleep continuity measures. The possibility that the improvement in sleep efficiency after olanzapine administration could have resulted from the resolution of underlying pathophysiological mechanisms of mania remains speculative.
In the present study, the main effect of the time of treatment on total REM activity and SWS was found in the first third of the night. Trends toward increased stages 2 and 4 of sleep architecture $(\mathrm{P}=0.08)$ and REM density $(P=0.07)$ were additional indicators of a time effect.

There are limited and contradictory data about the effects of pharmacological agents on REM sleep. Unmedicated manic patients often exhibit REM disturbances similar to those seen in depression: shortened REM latency and increased REM density (6), which can be corrected by lithium (9) and antidepressant medications (29). In healthy controls, 10-mg olanzapine increased the REM latency but decreased REM sleep time (1618) via an antagonistic effect on muscarinic cholinergic receptors. Previous studies have not found a significant increase in REM latency in schizophrenic patients receiving haloperidol (27), but acute administration of olanzapine to schizophrenics produced a significant increase in REM density (30). The anticholinergic effects of olanzapine may predict the decrease of REM activity and REM density in electroencephalogram sleep records. The identification of an inverse trend in the present study could be attributable to a time effect rather than to a direct drug effect. Since our patients improved clinically after treatment with olanzapine and haloperidol, it seems unlikely that a specific effect of the drug variable would be responsible for different alterations in REM measures.

An SWS deficit has been described in mania, although this finding has not been confirmed in studies with a greater number of patients $(6,10)$. Lithium carbonate did not affect delta sleep in manic or normal individuals (9), but was reported to be increased in depressed patients after lithium treatment (31). Acute administration of olanzapine to healthy volunteers and to schizophrenic patients increased SWS sleep (16,30). Previous studies (32) with the selective $5-\mathrm{HT}_{2 \mathrm{C}}$ antagonists ritanserin and ketanserin pre- 
dicted that administration of $5 \mathrm{mg}$ olanzapine represents an alive central occupancy of 5$\mathrm{HT}_{2 \mathrm{C}}$ receptors of at least $70 \%$ and may produce a 50\% increase in SWS (29). The antagonistic effects of olanzapine on brain 5- $\mathrm{HT}_{2 \mathrm{C}}$ receptors could well influence SWS, but our results showed that changes in SWS were more related to the time effect than to a direct drug effect. An alternative explanation may be that drug effects are more prominent acutely, so that after 6 weeks' treatment this effect could no longer be observed.

Unfortunately, most manic patients cannot cooperate sufficiently to participate in meaningful sleep studies, which could collect enough conclusive data. Drug treatment with antipsychotics or lithium carbonate tends to have a significant effect on sleep records. These difficulties are the main reasons that have limited the sample size of this study to 12 patients. Technically speaking, in the PSG procedures, the approach of visual ratings for SWS coupled with the absence of computerized assessments of PSG measures has restricted the interpretability of our findings. Pretest adaptation or acclimatization nights for the sleep laboratory procedure are desirable, but this requirement is hard to meet for agitated manics. Some PSG studies $(9,10)$ with manic patients have suggested that the first night effect is not so important, since no significant inter-night difference in PSG variables was detected. Another limitation of the present study is some baseline between-group difference for previous illness history and pre-treatment PSG measures, which may have biased the direction of the findings.

Aside from the difficulties in conducting sleep studies on restless and unmedicated manic inpatients, PSG records may provide information which sheds light on how manic states are affected by psychopharmacological agents, and which strengthens the neurobiological validity of mania. Determining the difference in the latency of onset of the therapeutic effect between a "sleep-promoting" antipsychotic (i.e., olanzapine), and "sleep-disrupting" antipsychotic (i.e., haloperidol) would be very important from a clinical-therapeutical point of view. Indeed, the pharmacological response to atypical antipsychotics and sleep abnormalities warrant further investigation to confirm their potential as trait/state markers of pathophysiological abnormality in manic conditions. The efficacy of olanzapine may be partially related to its favorable pharmacological profile in manic patients through its sleep continuity-promoting effects observed in PSG. Indeed, it is premature to recommend olanzapine as a fast-acting agent to improve sleep disturbances in psychiatric patients. Future studies should first repeat these preliminary findings, employing a larger sample size and a placebo group.

\section{References}

1. Mendels J, Hawkins DR. Longitudinal sleep study in hypomania. Arch Gen Psychiatry 1971; 25: 274-277.

2. Kupfer DJ, Heninger GR. REM activity as a correlate of mood changes throughout the night. Electroencephalographic sleep patterns in a patient with a 48-hour cyclic mood disorder. Arch Gen Psychiatry 1972; 27: 368-373.

3. Benca RM, Obermeyer WH, Thisted RA, Gillin JC. Sleep and psychiatric disorders. A meta-analysis. Arch Gen Psychiatry 1992; 49: 651-668.

4. Hartman E. Longitudinal studies of sleep and dream patterns in manic-depressive patients. Arch Gen Psychiatry 1968; 19: 312-329.

5. Gillin JC, Mazure C, Post RM, Jimerson D, Bunney WE Jr. An EEG sleep study of a bipolar (manic-depressive) patient with a nocturnal switch process. Biol Psychiatry 1977; 12: 711-718.

6. Hudson JI, Lipinski JF, Frankenburg FR, Grochocinski VJ, Kupfer DJ. Electroencephalographic sleep in mania. Arch Gen Psychiatry 1988; 45: 267-273.

7. Small JG, Milstein V, Medlock CE. Clinical EEG findings in mania. Clin Electroencephalogr 1997; 28: 229-235.

8. Small JG, Milstein V, Malloy FW, Medlock CE, Klapper MH. Clinical and quantitative EEG studies of mania. J Affect Disord 1999; 53: 217-224.

9. Hudson Jl, Lipinski JF, Frankenburg FR, Tohen M, Kupfer DJ. Effects of lithium on sleep in mania. Biol Psychiatry 1989; 25: 665668.

10. Hudson JI, Lipinski JF, Keck PE Jr, Aizley HG, Lukas SE, Rothschild 
AJ, et al. Polysomnographic characteristics of young manic patients. Comparison with unipolar depressed patients and normal control subjects. Arch Gen Psychiatry 1992; 49: 378-383.

11. Tohen M, Zarate CA Jr. Antipsychotic agents and bipolar disorder. $J$ Clin Psychiatry 1998; 59 (Suppl 1): 38-48.

12. Hirschfeld RMA. Guideline watch: Practice guideline for the treatment of patients with bipolar disorder. http://www.psych.org/psych pract/treatg/pg/prac_guide.cfm. Accessed August 15, 2006.

13. Tohen M, Sanger TM, McElroy SL, Tollefson GD, Chengappa KN, Daniel DG, et al. Olanzapine versus placebo in the treatment of acute mania. Olanzapine HGEH Study Group. Am J Psychiatry 1999; 156: 702-709.

14. Berk M, Ichim L, Brook S. Olanzapine compared to lithium in mania: a double-blind randomized controlled trial. Int Clin Psychopharmacol 1999; 14: 339-343.

15. McElroy SL, Frye M, Denicoff K, Altshuler L, Nolen W, Kupka R, et al. Olanzapine in treatment-resistant bipolar disorder. J Affect Disord 1998; 49: 119-122.

16. Sharpley AL, Vassallo CM, Cowen PJ. Olanzapine increases slowwave sleep: evidence for blockade of central 5-HT(2C) receptors in vivo. Biol Psychiatry 2000; 47: 468-470.

17. Lindberg N, Virkkunen M, Tani P, AppelBerg B, Virkkala J, Rimon R, et al. Effect of a single-dose of olanzapine on sleep in healthy females and males. Int Clin Psychopharmacol 2002; 17: 177-184.

18. Hubl D, Kleinlogel H, Frolich L, Weinandi T, Maurer K, Holstein W, et al. Multilead quantitative electroencephalogram profile and cognitive evoked potentials (P300) in healthy subjects after a single dose of olanzapine. Psychopharmacology 2001; 158: 281-288.

19. Wehr TA. Sleep-loss as a possible mediator of diverse causes of mania. Br J Psychiatry 1991; 159: 576-578.

20. Barbini B, Bertelli S, Colombo C, Smeraldi E. Sleep loss, a possible factor in augmenting manic episode. Psychiatry Res 1996; 65: 121 125.

21. Leibenluft E, Albert PS, Rosenthal NE, Wehr TA. Relationship between sleep and mood in patients with rapid-cycling bipolar disor- der. Psychiatry Res 1996; 63: 161-168.

22. American Psychiatry Association. Diagnostic and statistical manual of mental disorders. 4th edn. Washington: American Psychiatry Press; 1994.

23. First MB, Spitzer RL, Gibbon M, Williams JBW. Structured clinical interview for DSM-IV Axis I disorders - Patient edition (SCID - I/P, Version 2.0. 9/98 revision). New York: Biometrics Research Department, New York State Research Institute; 1998.

24. Young RC, Biggs JT, Ziegler VE, Meyer DA. A rating scale for mania: reliability, validity and sensitivity. $\mathrm{Br} J$ Psychiatry 1978; 133: 429-435.

25. Rechtschaffen A, Kales A. A manual of standardized terminology, techniques and scoring for sleep stages of human subjects. Washington: National Institute of Health Publications; 1968.

26. Spearing MK, Post RM, Leverich GS, Brandt D, Nolen W. Modification of the Clinical Global Impressions (CGI) Scale for use in bipolar illness (BP): the CGI-BP. Psychiatry Res 1997; 73: 159-171.

27. Taylor SF, Tandon R, Shipley JE, Eiser AS. Effect of neuroleptic treatment on polysomnographic measures in schizophrenia. Biol Psychiatry 1991; 30: 904-912.

28. Reus VI. Olanzapine: a novel atypical neuroleptic agent. Lancet 1997; 349: 1264-1265.

29. Sharpley AL, Walsh AES, Cowen PJ. Effect of nefazodone and lithium on sleep architecture in healthy men. $J$ Psychopharmacol 1996; 10: 26-29.

30. Salin-Pascual RJ, Herrera-Estrella M, Galicia-Polo L, Laurrabaquio MR. Olanzapine acute administration in schizophrenic patients increases delta sleep and sleep efficiency. Biol Psychiatry 1999; 46: 141-143.

31. Kupfer DJ, Wyatt RJ, Greenspan K, Scott J, Snyder F. Lithium carbonate and sleep in affective illness. Arch Gen Psychiatry 1970; 23: $35-40$

32. Sharpley AL, Elliott JM, Attenburrow MJ, Cowen PJ. Slow wave sleep in humans: role of 5-HT2A and 5-HT2C receptors. Neuropharmacology 1994; 33: 467-471. 